\title{
Free and open-source GIS-integrated hydrogeological analysis tool: an application for coastal aquifer systems
}

\author{
M. Perdikaki ${ }^{1} \cdot$ R. Criollo Manjarrez ${ }^{2} \cdot$ C. Pouliaris $^{1} \cdot$ R. Rossetto ${ }^{3} \cdot$ A. Kallioras ${ }^{1}$ (i)
}

Received: 3 December 2017 / Accepted: 23 June 2020 / Published online: 3 July 2020

(c) Springer-Verlag GmbH Germany, part of Springer Nature 2020

\begin{abstract}
This paper demonstrates the application of a recently developed free and open-source GIS-integrated hydrochemical-hydrogeological analysis tool (named AkvaGIS) for the management and interpretation of hydrogeological data with respect to a coastal aquifer system. The aforementioned tool is composed of a geospatial database implemented in Spatialite, complemented with a set of developed tools for the analysis, interpretation, and visualization of groundwater quality parameters and hydrogeological data. This ICT tool is part of the FREEWAT platform, an open-source and public domain GIS-integrated modelling environment based on groundwater flow and solute transport numerical models, including a water management and planning module. The case study that was used to perform a demonstration of the aforementioned tool, is a coastal aquifer system in Greece, suffering from both seawater intrusion and nitrate contamination as a result of extensive agricultural activities. It involves a complex hydrogeological environment incorporating karst and granular aquifer layers, subjected to different exploitation conditions. AkvaGIS was proved a useful ICT tool for the analysis and interpretation of the collected hydrogeological/hydrochemical data and results, which may be considered as a valuable tool for analyzing different aspects of aquifer systems.
\end{abstract}

Keywords AkvaGIS · FREEWAT platform · Hydrogeological analysis tool · QGIS · Aquifer system analysis · ICT tools · Water management

\section{Introduction}

The application of information communication technology (ICT) systems is continuously encouraged by several experts in the sector of water management, as many case studies have proved the necessity of such tools for a wide spectrum of problems and challenges. Among others, reported cases on the use of ICT tools in cross-disciplinary fields for the studies of water resources include:

- Physically based simulation modelling

- Data-driven modelling and management

A. Kallioras

kallioras@metal.ntua.gr

1 School of Mining and Metallurgical Engineering, National Technical University of Athens, Athens, Greece

2 Institute of Environmental Assessment and Water Research (IDÆA), Barcelona, Spain

3 Institute of Life Sciences, Land Lab, Sant'Anna School of Advanced Studies, Pisa, Italy
- Internet-based applications

- Optimisation and control

- Artificial neural networks

- Machine learning

In urban areas, these tools provide a set of technologies for effective water supply and treatment plan including stakeholder participation, water quality control, detection and prevention of emergency events, management of water economics, water distribution (Sempere-Payá et al. 2013) as well as decision-making tools for the effective surface water-groundwater management for sustainable cities (Rizou et al. 2018). These platforms are developed for monitoring and rehabilitation of contaminated groundwater systems via ICT-based monitoring networks that enable real-time aquifer monitoring and management (Miyata and Hata 2013; FAO 2017). All these different applications of ICT tools target to the adaptation of water management to national legislations and/or to the Water Framework Directive (WFD) 2000/60/ EU of the European Parliament (Pereira et al. 2003; Kundzewicz and Hattermann 2008). 


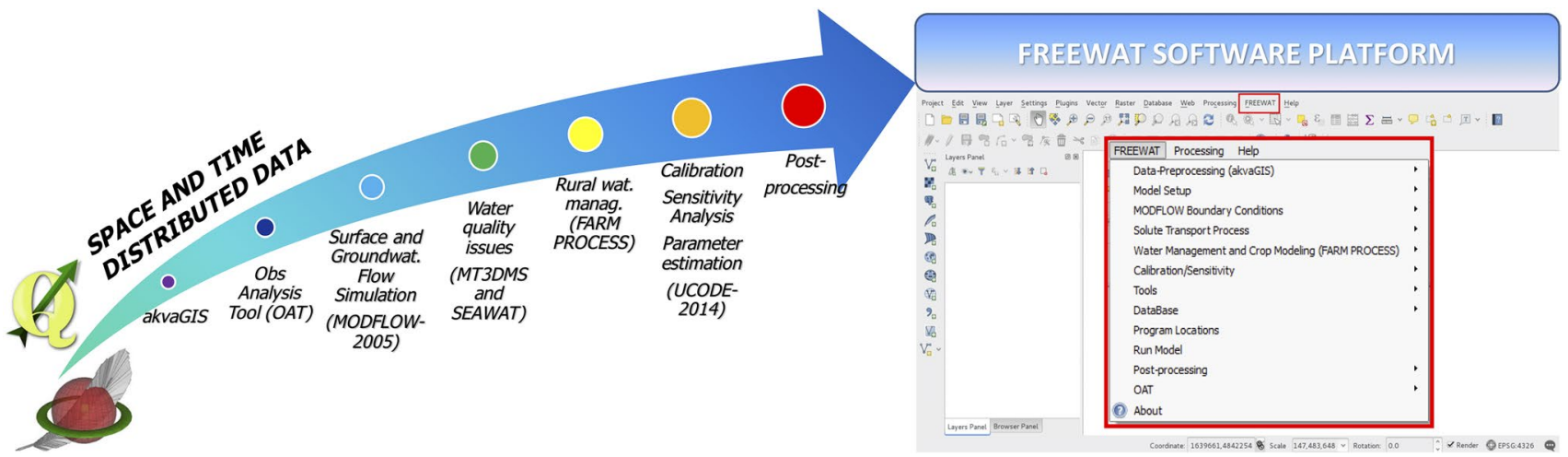

Fig. 1 Structure and components of the FREEWAT platform

Considering the above, it is well accepted that ICT tools and technologies-and in particular groundwater models-are able to substantially contribute to water management and to boost the implementation of Water Framework Directive 2000/60 as well as the accompanying water directives (e.g. Groundwater Directive, Nitrates Directive etc.). Additionally, it is further realized that ICT in the water domain can be proved valuable for: (i) the analysis of the conjunctive use of surface and ground water, (ii) the analysis of impacts related to land use and urban sprawling; and more general (iii) to evaluate the impacts of global changes on groundwater potential of aquifer systems.

Despite the aforementioned, free and open-source tools (and/or software platforms) are not widely available within the hydrogeological community, apart from the well-known MODFLOW "family" of USGS. In addition, numerically based GIS-integrated tools capable to perform spatial and temporal analysis on water quantity and quality issues are rather rare. One of the most famous graphical user interfaces, GUI, is the USGS ModelMuse (Winston 2009, 2014), which incorporates a group of the most famous codes such as MODFLOW-2005, MODFLOW-LGR, MODFLOWLGR2, MODFLOW-NWT, MODFLOW-CFP, MODFLOWOWHM, MT3DMS, SUTRA, PHAST, MODPATH, and ZONEBUDGET. A more focused GUI software that is also available from USGS is ModelMate (Banta 2011) facilitates model analysis by software applications that invoke model simulations as external processes; incorporating one model-analysis program, UCODE, and one model software program, MODFLOW-2005. In the domain of commercial GUIs, Visual MODFLOW Flex (Waterloo Hydrogeologic 2017), and groundwater modeling system-GMS-(AQUAVeo 2017) are the most widely known. Visual MODFLOW Flexin corporates standard codes for groundwater flow and contaminant transport, analysis, and calibration tools, and 3D visualization capabilities; while GMS is a software system available for performing groundwater simulations in a three-dimensional environment giving also the ability for
3D visualization. From all the above GUIs, the most critical feature that was missing until today is the integration of the modeling software within a GIS platform. This feature provides the user the facility to work with a homogenized set of files and data, for both modeling and GIS activities.

FREEWAT $^{1}$ Platform is a free and open-source public domain GIS-integrated modelling environment for the simulation of water quantity and quality in surface and groundwater with acombined water management and planning module. FREEWAT is developed as a composite plugin for the well-known QGIS open-source geographical information system desktop software.

As composite plugin, FREEWAT is designed as a modular ensemble of different tools; some of them can be used independently, while some modules require the preliminary execution of other tools. In the above framework, the following tool classifications can be defined (Fig. 1):

- Tools for the analysis, interpretation, and visualization of hydrogeological and hydrochemical data and quality issues, also focusing on advanced time series analysis, embedded in the AkvaGIS module (presented in this study).

- Additional tools for general GIS operations targeting on input data preparation and post-processing functionalities (OAT-observation and analysis tool).

- Models related to the hydrological cycle and water resources management: groundwater flow and contaminant transport models (MODFLOW-2005, MT3DMS, and SEAWAT), crop growth models, management and optimization models of irrigation water and rural issues (FARM PROCESS).

\footnotetext{
1 Developed within the framework of FREEWAT project (https:// www.freewat.eu) that received funding from the European Union's Horizon 2020 research and innovation programme under grant agreement No 642224.
} 
- Tools to perform model calibration, sensitivity analysis, and uncertainty quantifications (Poeter et al. 2014).

The hydrogeological analysis tool-AkvaGIS-, presented in this paper, is created to complement the functionalities of the FREEWAT platform in the same QGIS environment. AkvaGIS is composed of a geospatial database implemented in Spatialite and a set of tools which are designed to improve the management, visualization and interpretation of collected hydrogeological and hydrochemical data. This module that is integrated into the FREEWAT platform, allows the user: (1) to manage and query any hydrogeological measurement (e.g. groundwater hydraulic heads, groundwater abstractions etc.) that are stored within the database; (2) to apply one or several query criteria (e.g. time interval, groundwater measurement) and to combine them for advanced spatio-temporal queries on the hydrogeological data stored in the database; (3) to create thematic maps ( e.g. groundwater quality maps) of the selected points, time interval and parameters; (4) to calculate some general statistics, i.e. minimum, maximum or average for each selected hydrogeological parameter, such as piezometric level, pumping rates etc.; (5) to query the depth or the thickness of the defined hydrogeological units and to represent these values in a map as point features, with the possibility to interpolate results.

This set of tools forms a part of wider framework developed into FREEWAT (the module pre-processing tools; AkvaGIS) created to facilitate the pre-processing of further hydrogeological analysis and interpretations (specifically hydrochemical analysis). This study presents the application of AkvaGIS module on Marathon coastal aquifer system-a typical coastal hydrosystem that suffers from seawater intrusion and nitrate contamination-that is used to realize the demonstration of the aforementioned tool.

\section{AkvaGIS application}

\section{General setting of the study area}

Marathon plain is located at the NE of Attica Peninsula in Greece and is extended in an area of approximately $40 \mathrm{~km}^{2}$. It is a coastal aquifer system which is in hydraulic contact with the Mediterranean Sea having typical characteristics of a semi-arid region, in terms of climatic, hydrological, and hydrogeological conditions. At the east, the area includes a naturally occurring wetland with the characteristics of a distinct ecosystem linked to a typical coastal hydrogeological system of a semi-arid region. This wetland presently degraded-in quantitative terms-due to intensive anthropogenic activities through the past and the present time. Most of the plain area is mainly used for agricultural and touristic activities, while there are limited parts of permanent residences. This specific land use results to extensive human activities in summertime, a fact that leads to regional and seasonal imbalance in surface water and groundwater needs and demands.

\section{Geology and hydrogeology}

A simplified description of the geological structure of the surrounding area involves a set of marble formations with an underlying layer of schist (Fig. 2). The marble formation is divided into five subunits according to Melissaris and Stavropoulos (1999), while the overall thickness exceeds $400 \mathrm{~m}$. The alluvial plain which is composed of quaternary and neogene deposits, is in hydraulic contact with all the surrounding marble units (classified according to their hydraulic conductivity).

The hydrogeological setting involves a multi-layer aquifer system that consists of the upper unconsolidated formation dominated mostly by alluvial deposits and the surrounding multi-porosity karstified aquifer units overlying the impermeable schist layer (Fig. 2). The hydrogeological boundaries of the investigated system include the marble formations at the northern and northwestern part of the plain, the Mediterranean Sea along the coastline at the southern part and the coastal wetland at the eastern part of the plain where the area is hydraulically disconnected with the upper unconsolidated layer.

The characteristics of the two groundwater units differ. The three karstified units that are in contact with the alluvial plain are of great thickness (more than $400 \mathrm{~m}$ ) and have a hydraulic conductivity that ranges between $10^{-5}$ and $10^{-4} \mathrm{~m} / \mathrm{s}$ (Siemos 2010). The karstic system is recharged through direct infiltration from precipitation and discharges into the alluvial coastal formation as well as into the Mediterranean Sea through diffuse flow. A major discharge point of the karstified formation is Makaria spring at the NE part of the plain through "Marathon" marbles with a mean discharge rate of $810 \mathrm{~m}^{3} / \mathrm{h}$ (Perleros 2001). The alluvial aquifer system has a thickness of a few meters up to $80 \mathrm{~m}$ and it is a layer of lower permeability with hydraulic conductivity values from $10^{-6}$ to $10^{-5} \mathrm{~m} / \mathrm{s}$ (Siemos 2010). The unconsolidated unit is mainly recharged through direct infiltration from precipitation, through lateral inflows and a karstic spring from the surrounding karstified marble and finally from irrigation return flows as a result of the irrigation activities that take place within the area. The alluvial formation is considered to be an unconfined one-at most of its surface area—with a varying grain size distribution due to clay, silty clay, gravels, and sand materials. The occurrence of extended clay layers within the upper part of the granular aquifer, results to the formation of a limited confined layer with different hydrodynamic conditions in many parts of the aquifer domain. 


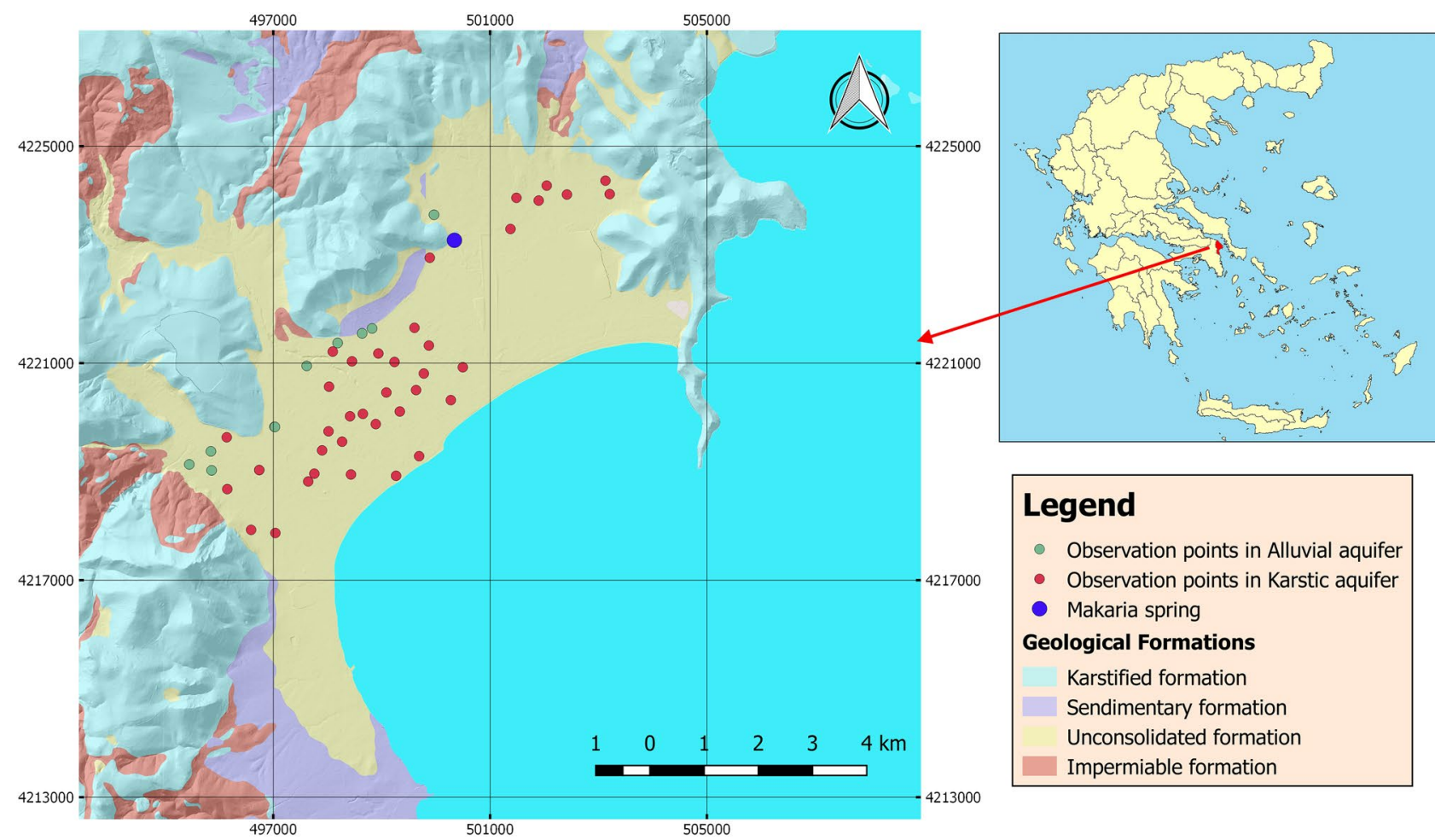

Fig. 2 Hydrogeological map of Marathon plain

\section{Hydrochemical reference problems}

Both karstic and granular aquifer formations suffer from seawater intrusion (Koumantakis et al. 1993; Psychoyou et al. 2007; Tzanis et al. 2008) as a result of considerable pumping activities in the entire area. The problem is more intensified in the unconsolidated formation as multiple groundwater wells that are used, change the hydrodynamic conditions and make the system more vulnerable. Groundwater contamination due to elevated nitrate concentrations has been reported in the study area from previous studies (Melissaris and Stavropoulos 1999; Psychoyou et al. 2007; Sotiropoulos et al. 2007), while the continuous use of fertilizers intensified the problem during the last decade.

\section{AkvaGIS module application- hydrochemical analysis}

The analysis and interpretation of the collected hydrochemical and hydrogeological data were carried out using AkvaGIS set of tools which is integrated in the FREEWAT platform. As mentioned above, the main goal of this module is to manage groundwater quality and quantity issues by analyzing, interpreting, comparing, and visualizing in situ and hydrochemical measurements in a GIS environment. The integration of a data analysis tool in a GIS environment was accomplished within QGIS software, a free and open-source geographic information system. AkvaGIS as a FREEWAT platform module is based on the developments of previous works carried out by Velasco (2013), Velasco et al. (2014), Alcaraz (2016), and Criollo et al. (2016). AkvaGIS has been designed as an object-oriented code avoiding code repetition to reduce errors and improve the maintainability. The code (current version 1.0) is developed in Python and it is freely available, while the Python-related dependencies that AkvaGIS applies are the Qt version 4 Python wrapper (PyQt4), a Python 2D plotting library that creates quality figures in a variety of hardcopy formats and interactive environments across platforms (Criollo et al. 2019).

The AkvaGIS database is implemented in RDBMS Spatialite while its structure facilitates: (1) the data standardization and harmonization, (2) the storage and management of large amount of spatial features and time-dependent data and (3) the creation and the execution of queries. SpatiaLite an open-source library intended to extend SQLite Database engine with spatial functions and to support fully fledged Spatial SQL capabilities. SQLite is a database management system (DBMS) which is simple, robust, easy to use, and very lightweight.

The hydrochemical information related to each spatial point (e.g. groundwater sample) contains the dates of each collected sample, the dates of the physical and chemical parameters analysis, as well as their corresponding values 


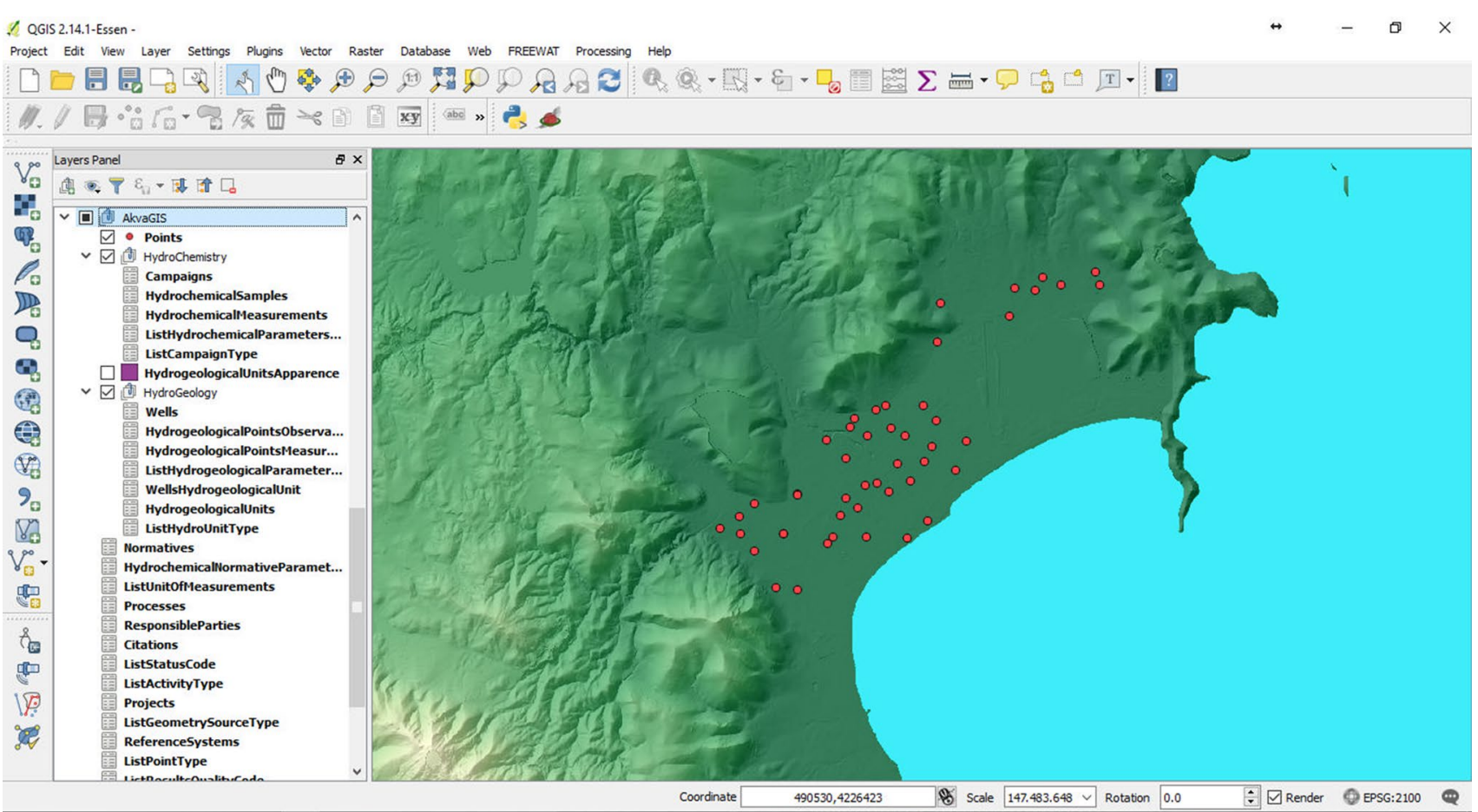

Fig. 3 AkvaGIS database in QGIS desktop environment

and units. The list of the analysed parameters is stored in a library/catalogue that can be updated by the user. In the same way, the hydrogeological information corresponds to a spatial point where the hydrogeological measures were observed. The default hydrogeological parameters available in the library/catalogue are: flow rate, depth to water, pressure, and head stored, while this list of parameters can be customized by the user.

Figure 3 shows the AkvaGIS database that was developed for Marathon plain in QGIS, combining available data of observation points, groundwater samples, hydrochemical measurements, and the digital elevation model (DEM) of the area of interest.

The samples used for the application of AkvaGIS, collected from both karstic and alluvial aquifer (Fig. 2), during the wet (May) and dry (October) period of 2016. Each sample was subjected to field measurements of specific electrical conductivity, $\mathrm{pH}$, temperature, and dissolved oxygen. In the alluvial aquifer, 39 sampling points were used for the application of AkvaGIS tools, while in the karstic 9 sampling points were available. Although there is a limited number of existing boreholes in the karstic formation, the sampling points are distributed uniformly in the aquifer layer.

After the sampling campaign, the water samples were transferred to the laboratory, where chemical analysis was conducted to specify the major ions of every sample $\left(\mathrm{Ca}^{2+}\right.$, $\mathrm{Mg}^{2+}, \mathrm{Na}^{+}, \mathrm{K}^{+}, \mathrm{HCO}_{3}{ }^{-}, \mathrm{SO}_{4}{ }^{2-}, \mathrm{Cl}^{-}$, and $\mathrm{NO}_{3}{ }^{-}$). The results were introduced in AkvaGIS database where the following specific step-wise procedure was performed, so as to specify the range of seawater intrusion and the occurrence of other agrochemical pollutants in both groundwater units (unconsolidated and karstic aquifer). The following diagram (Fig. 4) describes the main and most important steps for the construction of an AkvaGIS project and the extraction and interpretation of the results.

In more detail, collected data are imported in QGIS as a csv file with a specific format. For hydrochemical analysis, the main information needed, is the sampling points for spatial representation, the sampling campaigns, the samples of all campaigns and finally the hydrochemical measurement of each sample to analyze and interpret the information given.

The inserted files can be easily copied in AkvaGIS, using the copy-paste tool of QGIS table. The procedure that was followed for the construction of AkvaGIS database for Marathon plain, is presented in the following images (Figs. 5, 6, 7 and 8). For the specific case study, 48 sample points were introduced in the AkvaGIS demonstration database ( 9 points of the karstic aquifer and 39 points of the alluvial aquifer), two campaigns (May 2016 and October 2016) and 9 chemical elements for each sample. At this point, it has to be noted that the tables of the database can be easily modified (delete, add or edit samples and data) at any time during the processing, using the features of QGIS attribute tables or by the "Manage Hydrochemical Data" GUI (graphical user interface) in which the user can edit the information of the sampling 


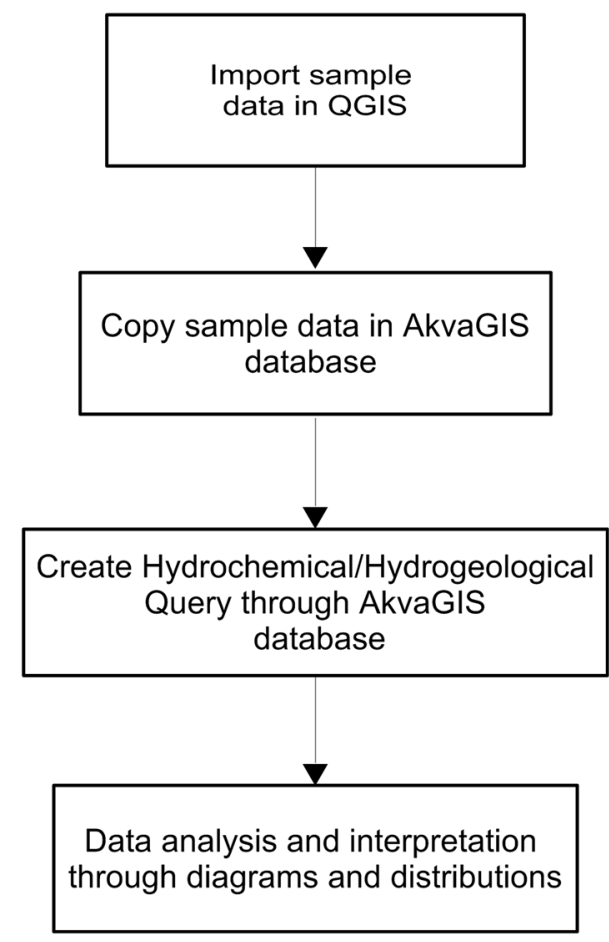

Fig. 4 Schematic representation of the main steps for data analysis using AkvaGIS points, add or edit samples, campaigns, and hydrochemical measurements one by one or massively, using "csv" files.

The data processing in akvaGIS module, is enabled by the "Hydrochemical Spatial Query" option. It is a query that is created by selecting a point or a set of points on QGIS interface, so as to make a group that represents sampling sites (points) in the database. Each query collects the information of the selected dataset and it can then be categorised by other query criteria such us period of time of sampling or campaigns so that (Fig. 9). The hydrochemical spatial query created, can be stored in the database and then used by all the hydrochemical tools that are included in akvaGIS toolbar.

The main use of the hydrochemical query is the construction of hydrochemical diagrams (piper, SAR, SBD and stiff plots), hydrochemical parameter time plots which visualises the evolution of a query's parameter through different campaigns, chemical ions balance report and chemical parameter map of a specific hydrochemical parameter. Once the user has performed the selected query created with the hydrochemical spatial query tool then a variety of interpretation diagrams (such as Piper, SAR etc.) can be produced only if the measurements required for the creation of this diagram are available. An example of production of a Piper diagram through the AkvaGis module is given in Fig. 10.

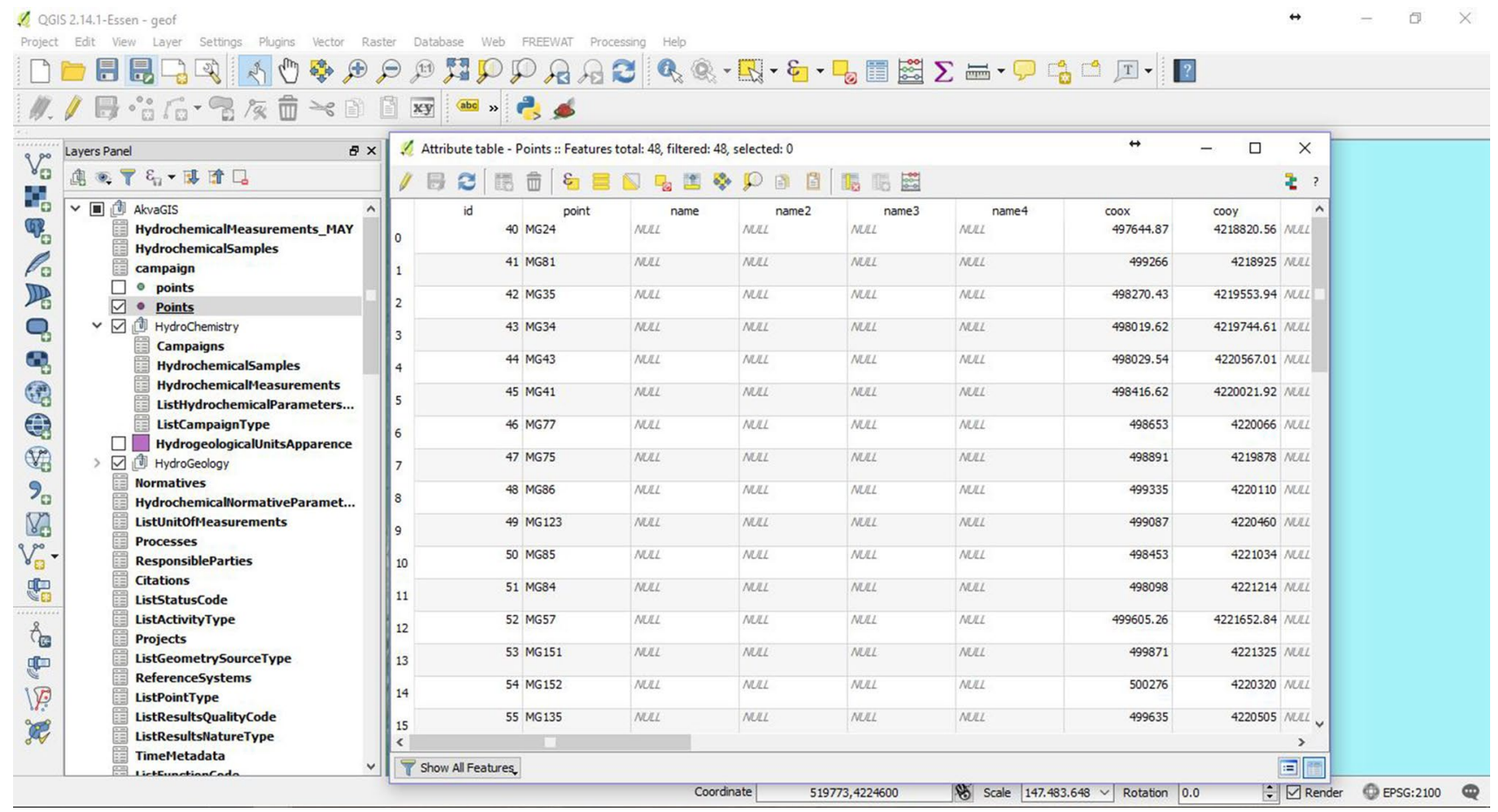

Fig. 5 Sampling points attribute table in AkvaGIS database 


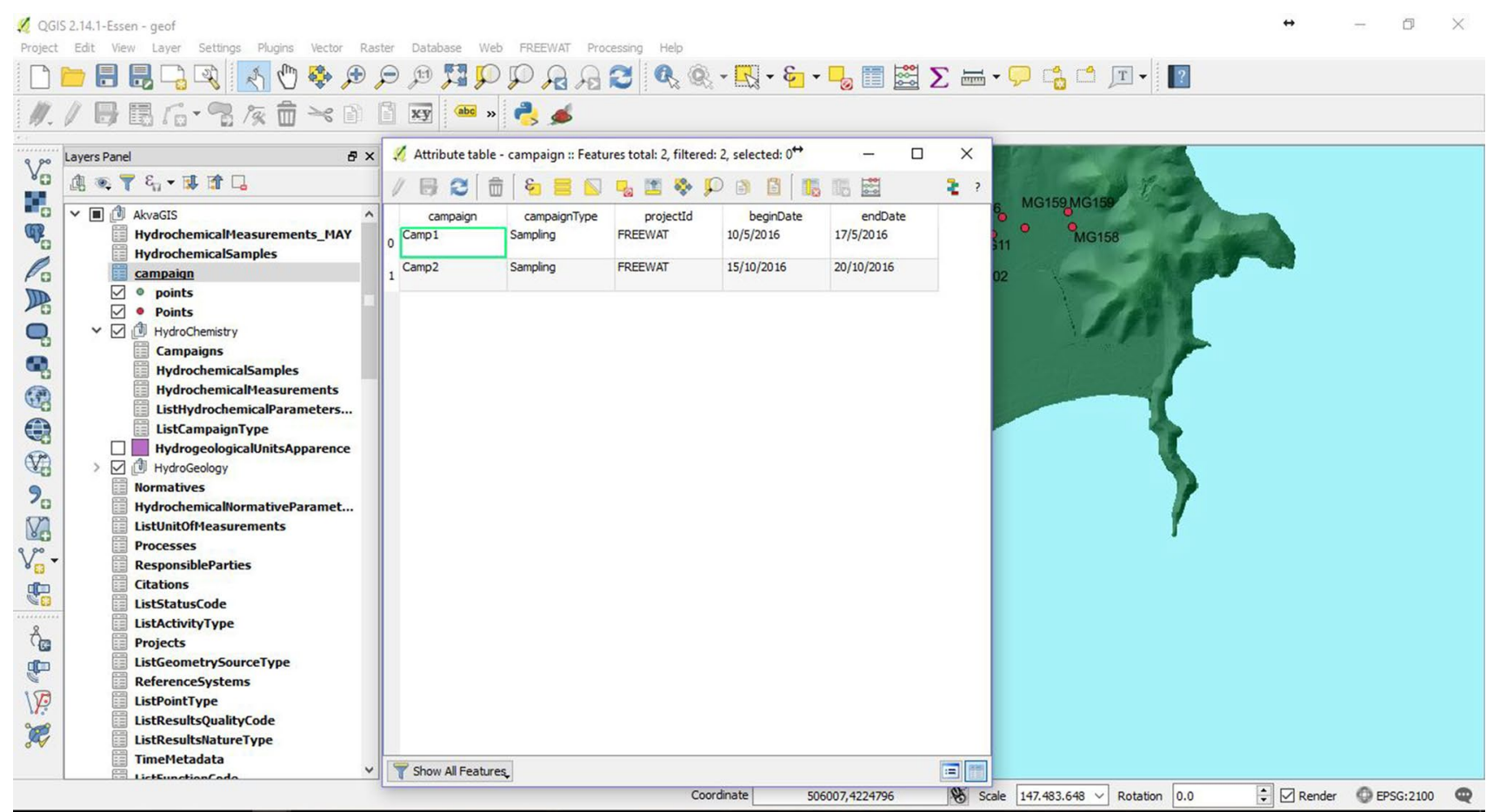

Fig. 6 Campaigns attribute table in AkvaGIS database

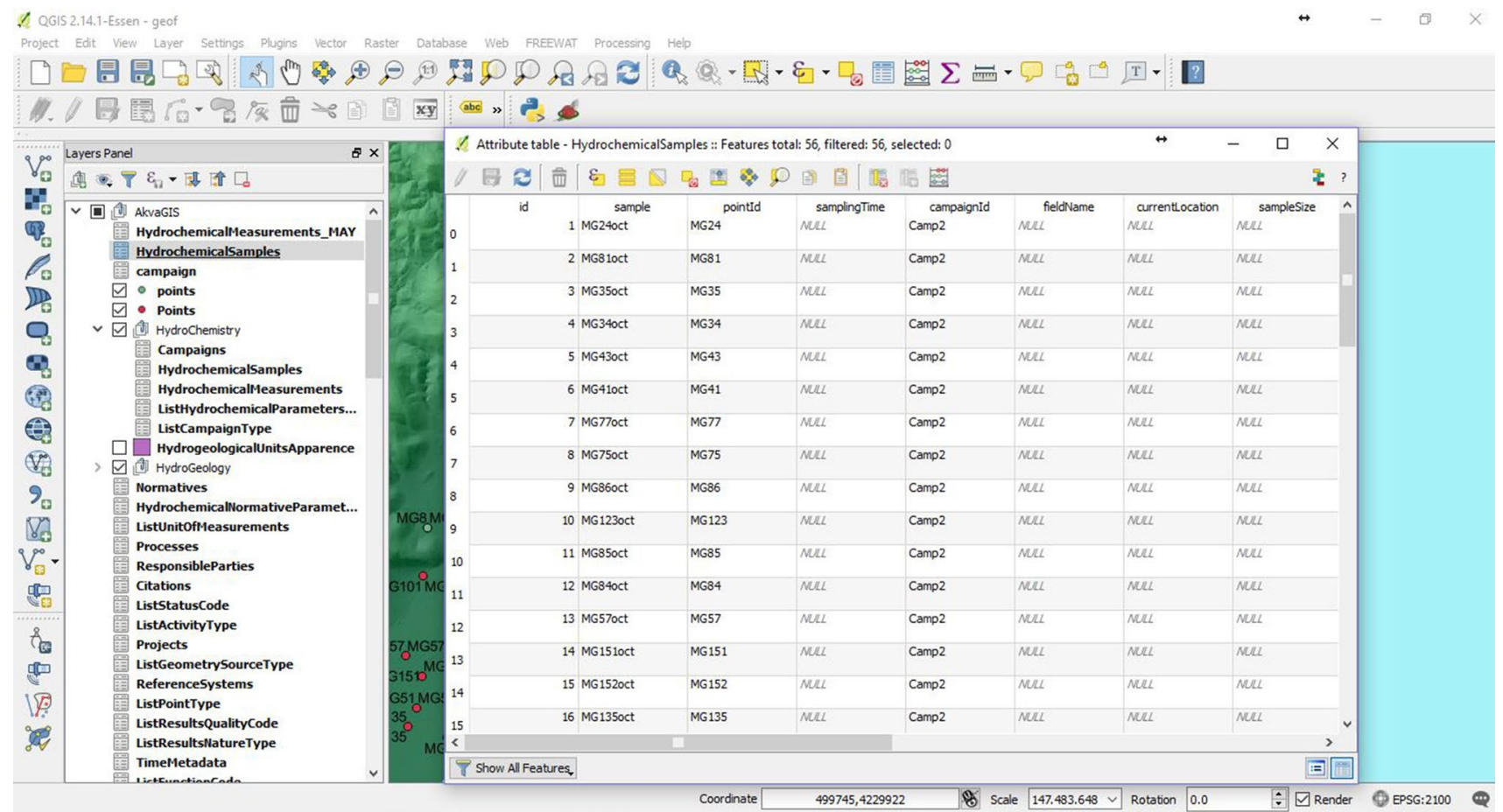

Fig. 7 Hydrochemical samples attribute table in AkvaGIS database

A special feature of AkvaGIS module, is the "Parameter Normative Map" tool that enables the user to demonstrate a queried parameter, classified according to the thresholds that are established by a specific guideline such as Water Framework Directive, Nitrates Directive and other related national or international water policies and regulations. 


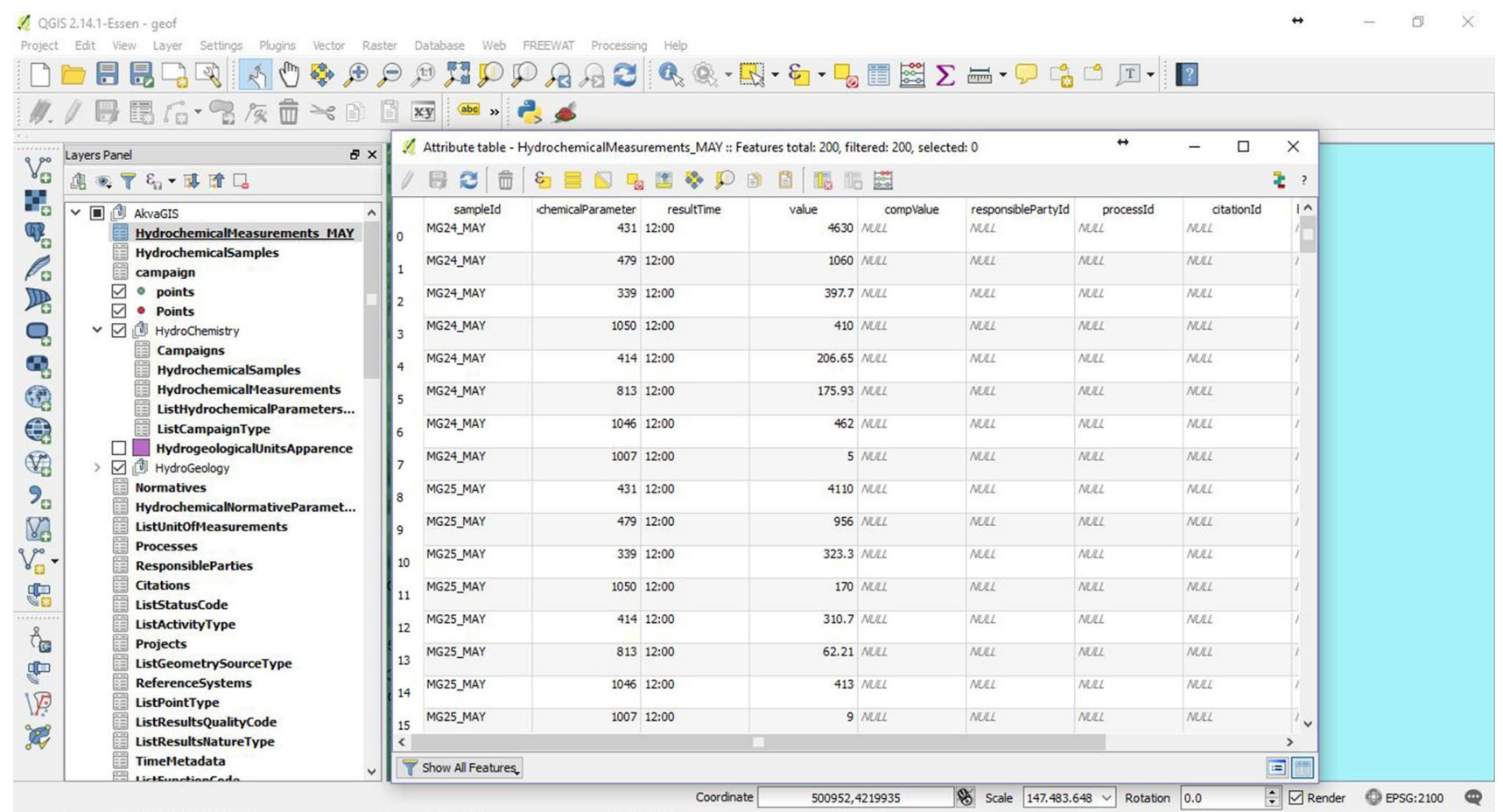

Fig. 8 Hydrochemical measurements attribute table in AkvaGIS database

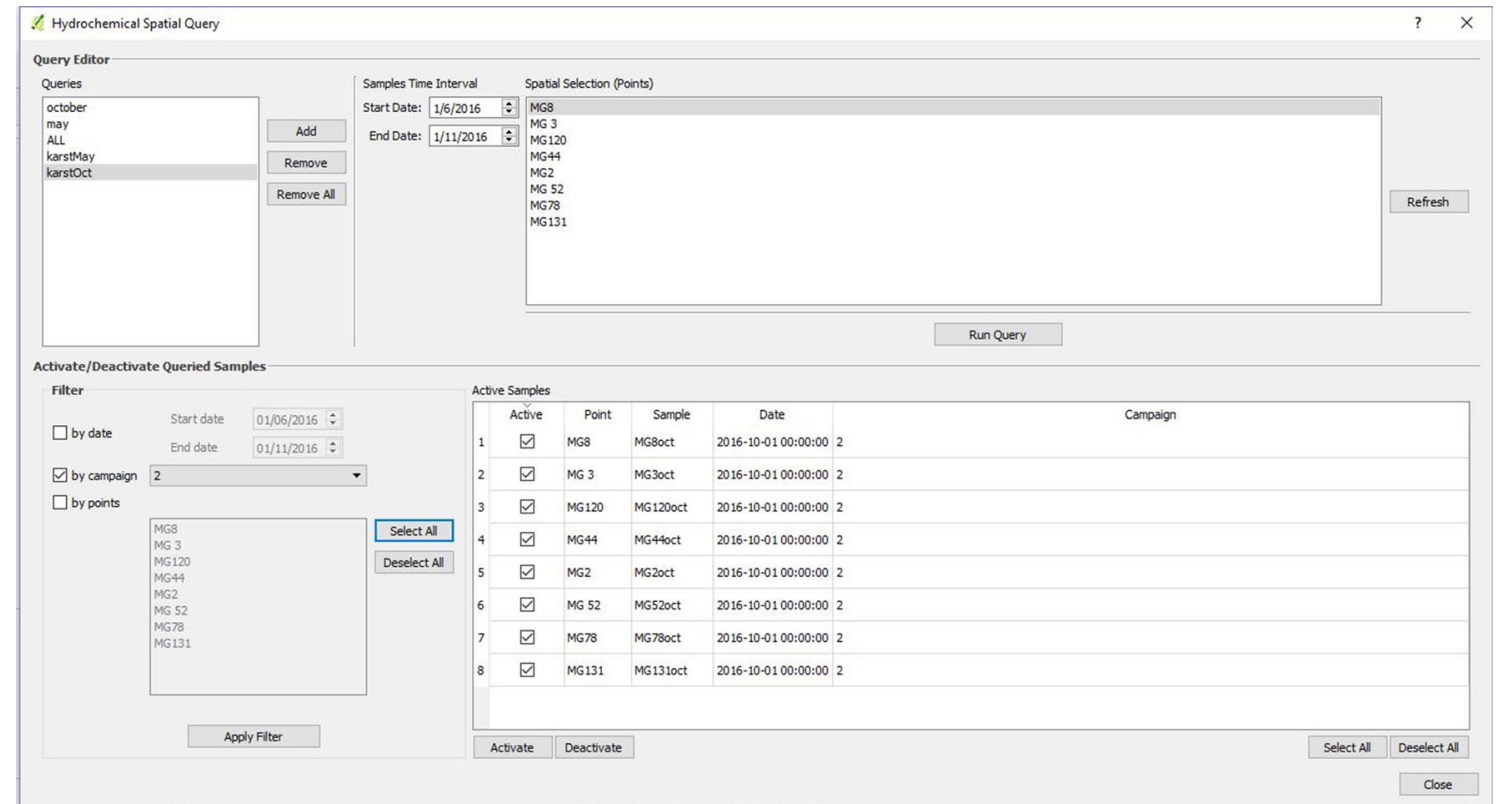

Fig. 9 Hydrochemical spatial query

Each directive that is used for classification can be added manually in the "Normatives" attribute table (Fig. 11), while the user can also arrange the thresholds for the chemical parameter of each regulation in the "Hydrochemical Normative Parameters" attribute table of AkvaGIS database (Fig. 12). The normatives can then be used for the construction of thematic maps, presenting the concentration limits of a chemical parameter map of a query. 
(a)

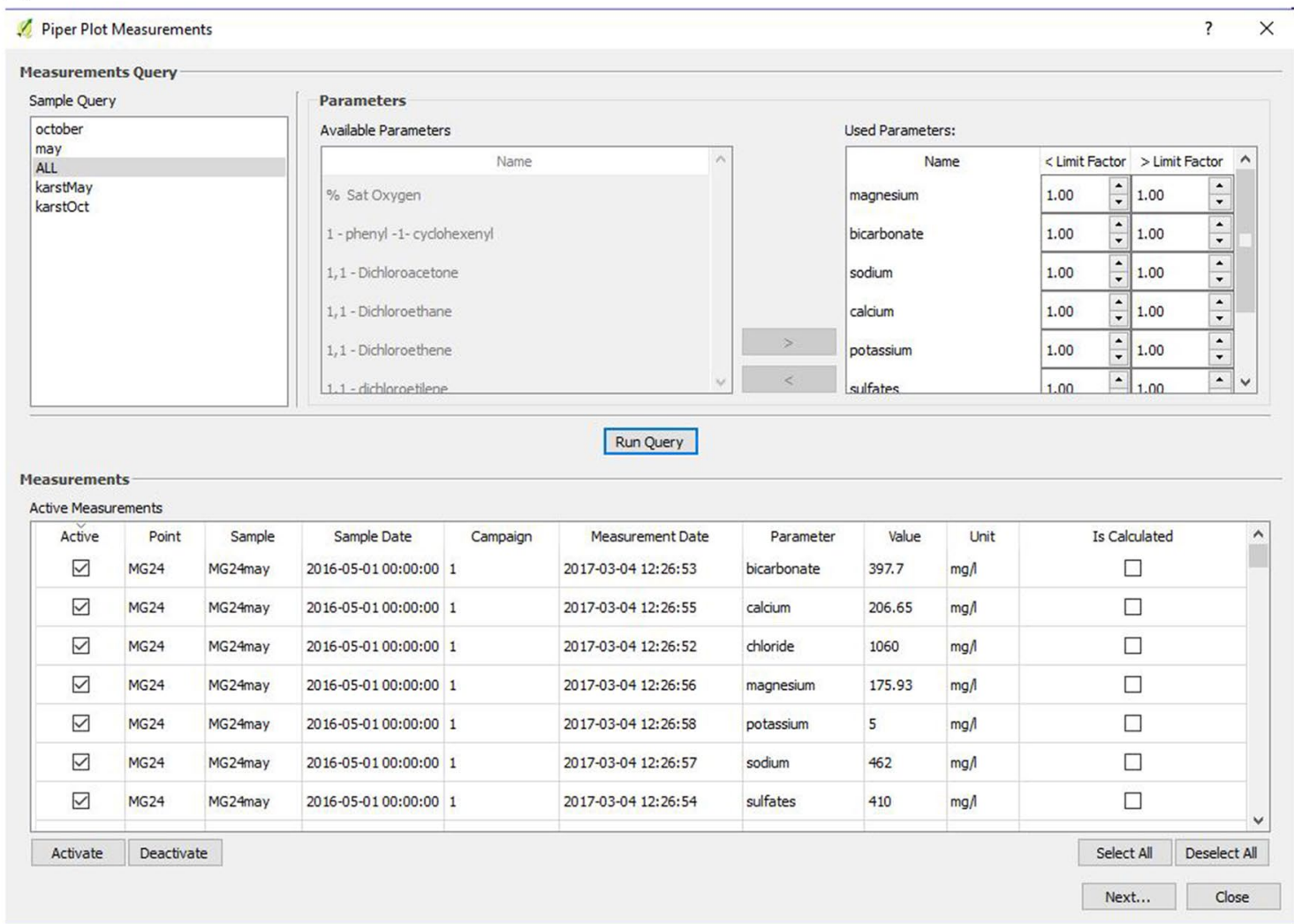

(b)

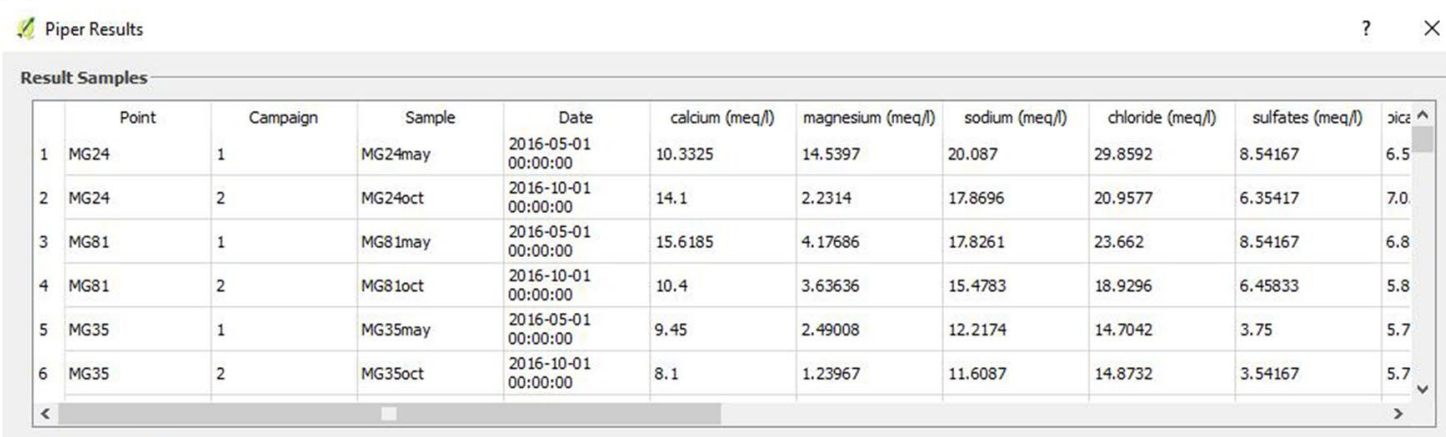

$\checkmark$ Plot configuration

General Plot Settings -

Plot Size

$X$ (pixels): $860 \quad$ Y (pixels): 720 ;

DPI 80

Title

\begin{tabular}{|c|c|c|c|c|c|c|c|}
\hline \multirow{2}{*}{$\begin{array}{l}\text { Title: } \\
\text { Font type: }\end{array}$} & \multicolumn{7}{|l|}{ Piper Plot } \\
\hline & Arial & $v$ & Font color: & 1. & Font size: & 24.0 & $\div$ \\
\hline Line & & & & $\square$ Legend & & & \\
\hline & Type: & dashed & $r$ & Number of columns: & 4 & $:$ & $\nabla$ Automatic \\
\hline & Colorset: & jet & x & Marker scale: & 1.0 & $\div$ & \\
\hline & Line width: & 0.5 & $\div$ & Font size: & 14.00 & $\div$ & \\
\hline
\end{tabular}

$\square$ Marker

\begin{tabular}{rll} 
Type: & filled set \\
Colorset: & jet \\
Size: & 10.5 & \\
Edge width: & 0.5 & - \\
\hline
\end{tabular}

Font size: $14.00 \quad-$

$\checkmark$ Piper

Fig. 10 Construction of a piper plot (a) using a hydrochemical spatial query (b) 
1 QGIS 2.14.1-Essen - geof

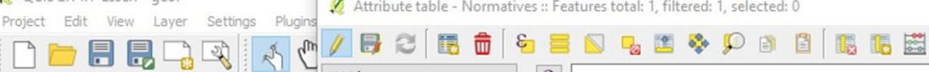

\begin{tabular}{|l|l} 
HydrogeologicalUnitsA \\
HydroGeology
\end{tabular}

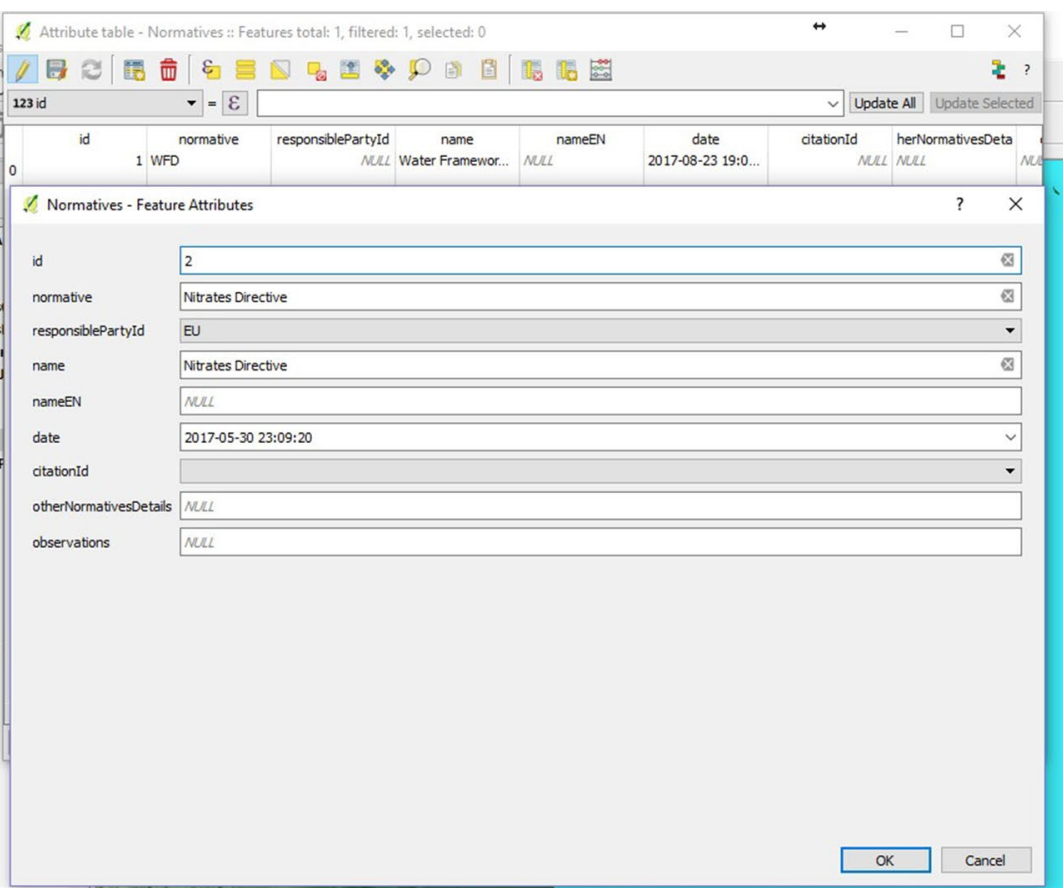

Fig. 11 New normative addition

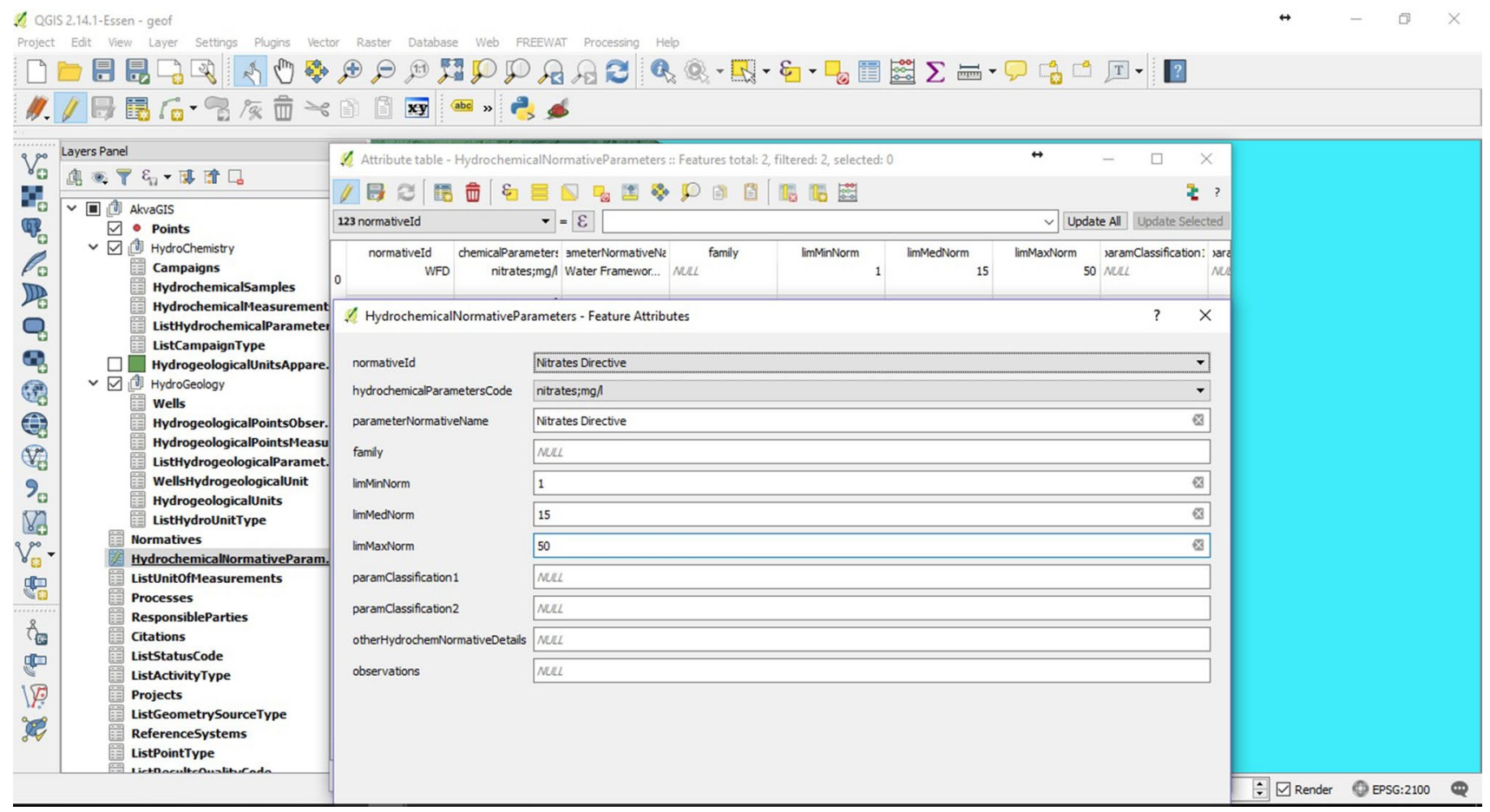

Fig. 12 Normative parameter thresholds addition 
Fig. 13 Chlorides spatial distribution (May 2016)
Chloride concentration (mg/lt) of May 2016

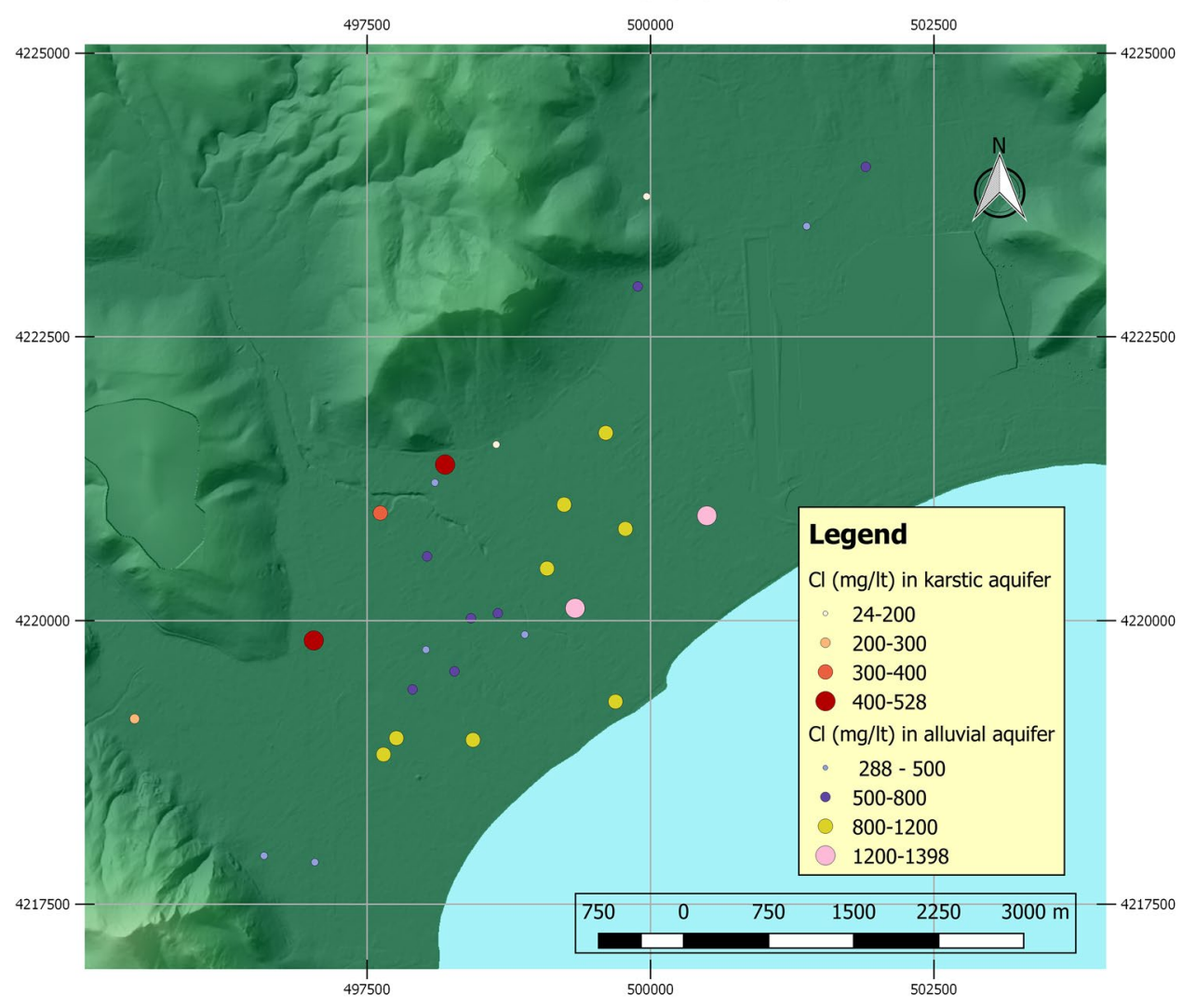

\section{Results and discussion}

AkvaGIS module was used to visualise the groundwater condition of the two aquifer units (karstic and alluvial formations) in Marathon plain to specify the exact condition of seawater intrusion through chloride concentration, nitrate contamination according to the EU thresholds and the general groundwater deterioration through hydrochemical plots.

A useful tool to monitor the seawater encroachment in an aquifer is the production of thematic maps that represent ion concentrations with chloride being the most suitable indicator to specify the range of saline water in a contaminated aquifer that is also considered a key factor for the characterization of the groundwater use.

The chemical analysis of the samples collected during the wet and dry period of 2016 in Marathon plain, confirms the high concentration of ions due to the seawater intrusion in both coastal aquifer types (alluvial and karstic). AkvaGIS module was proved a helpful tool to visualise the concentration of chloride ions in the vicinity of Marathon. Figure 13 presents thematic maps of chloride concentration for the two periods, using the "Chemical Parameter Map" tool of AkvaGIS and the "Print Composer" module of QGIS.

In the unconsolidated formation, the calculated values of $\mathrm{Cl}^{-}$ions for May indicate a hydrochemical evidence of seawater intrusion with high ions range between 288 and
$1400 \mathrm{mg} / \mathrm{lt}$. The highest concentration is mainly observed at the central part of the area and near the coast where the $\mathrm{Cl}^{-}$ions exceed $800 \mathrm{mg} / \mathrm{lt}$ while the salinity is being depleted in the NE and SW parts of the plain where the unconsolidated formation meets the karstified one. The high concentration of chloride ions at the central part of the alluvial aquifer, is a result of the multiple wells and boreholes in the area and the intensive agricultural activities. On the contrary, in the karstic formation, there is a lower fluctuation in the concentration of chloride ions as the values range between 25 and $528 \mathrm{mg} / \mathrm{lt}$. In both formations, there are values that exceed the chloride concentration limit of 200-250 mg/lt that is given from the European Commission, according to Annex 3 of Groundwater Directive. The deviation from the European thresholds is far more notable in the shallow unconsolidated formation where all the groundwater samples are above the chloride concentration limits.

The wide difference between ion concentrations in the two groundwater formations arises from the differences in hydrodynamic conditions, hydraulic features and groundwater recharge and discharge. A very important reason to the different ions concentrations is the discharge of groundwater due to pumping, as it affects the alluvial aquifer more than the karstic unit as a result of the multiple wells and drills in the shallow layer and the limited boreholes in the karstic one. 
Fig. 14 Piper plot for groundwater samples of alluvial aquifer (May 2016)
Fig. 15 Piper plot for groundwater samples of karstic aquifer (May 2016)

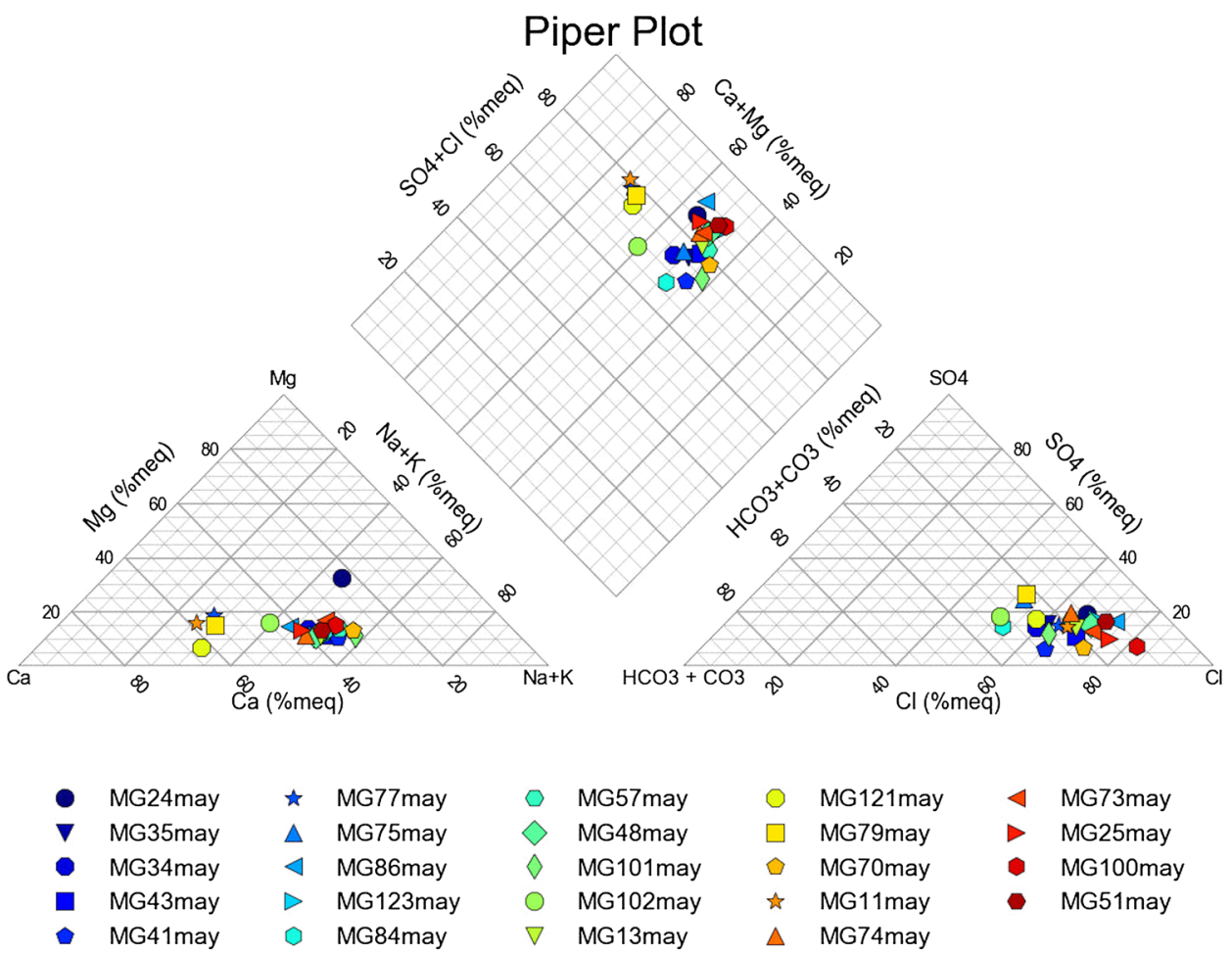

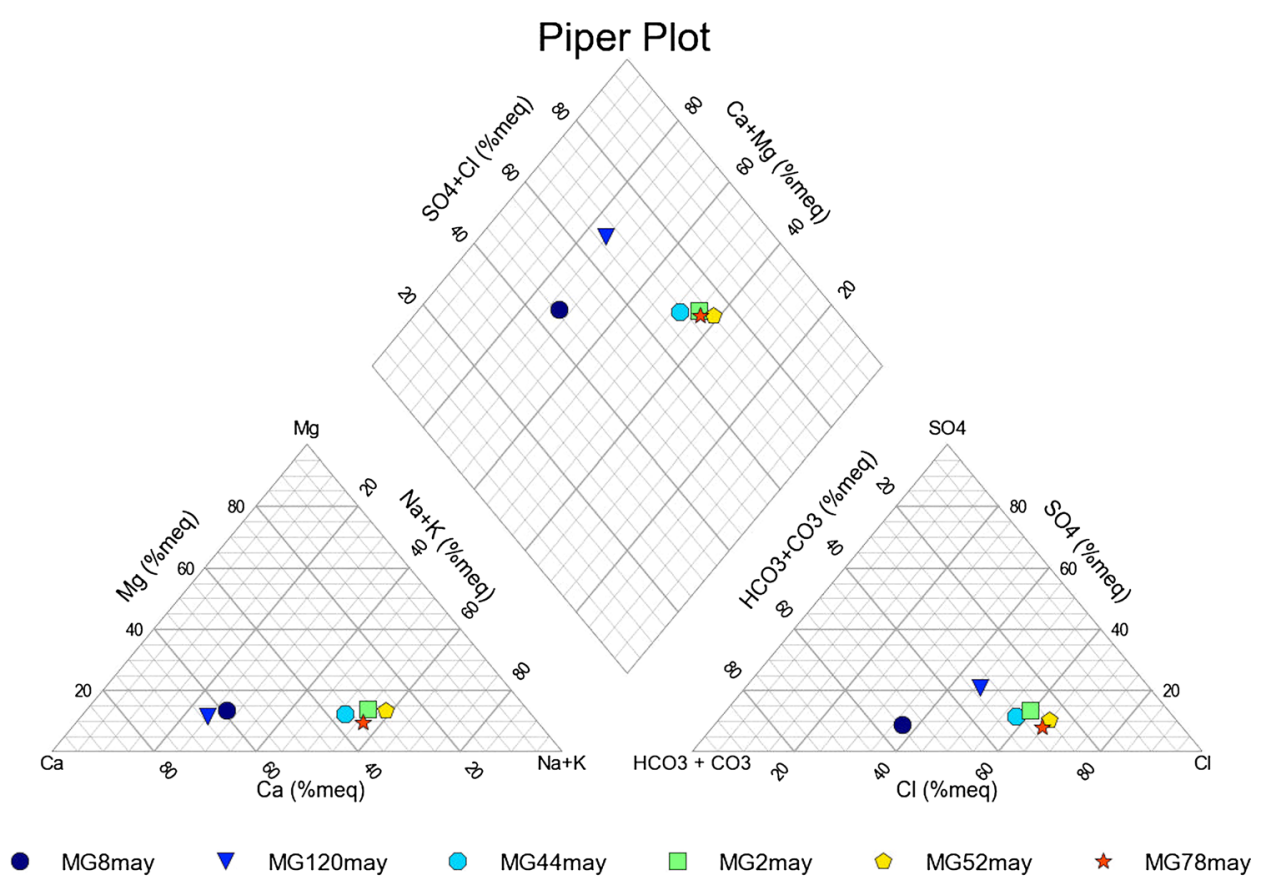

In Fig. 14, a piper diagram is presented, for groundwater samples of the alluvial formation collected in May 2016 and it was created with the "Piper plot" tool of AkvaGIS. The plot reveals the domination of $\mathrm{Na}-\mathrm{Ca}-\mathrm{Cl}$ groundwater type as the high concentration values of chloride and sodium are caused by the saltwater intrusion, while calcium ions might be related to the presence of carbonate rocks in the whole area of Marathon plain. In addition, according to Appelo and Postma (2005), the aquifer samples show evidence of ion exchange as all the samples, are plotted between the intrusion and mixing zone, another evidence of the seawater intrusion occurrence.

In Piper plot of Fig. 15, groundwater samples of kartic aquifer in May 2016 are demonstrated. The dominant ions 
Fig. 16 SAR plot for alluvial aquifer (May 2016)

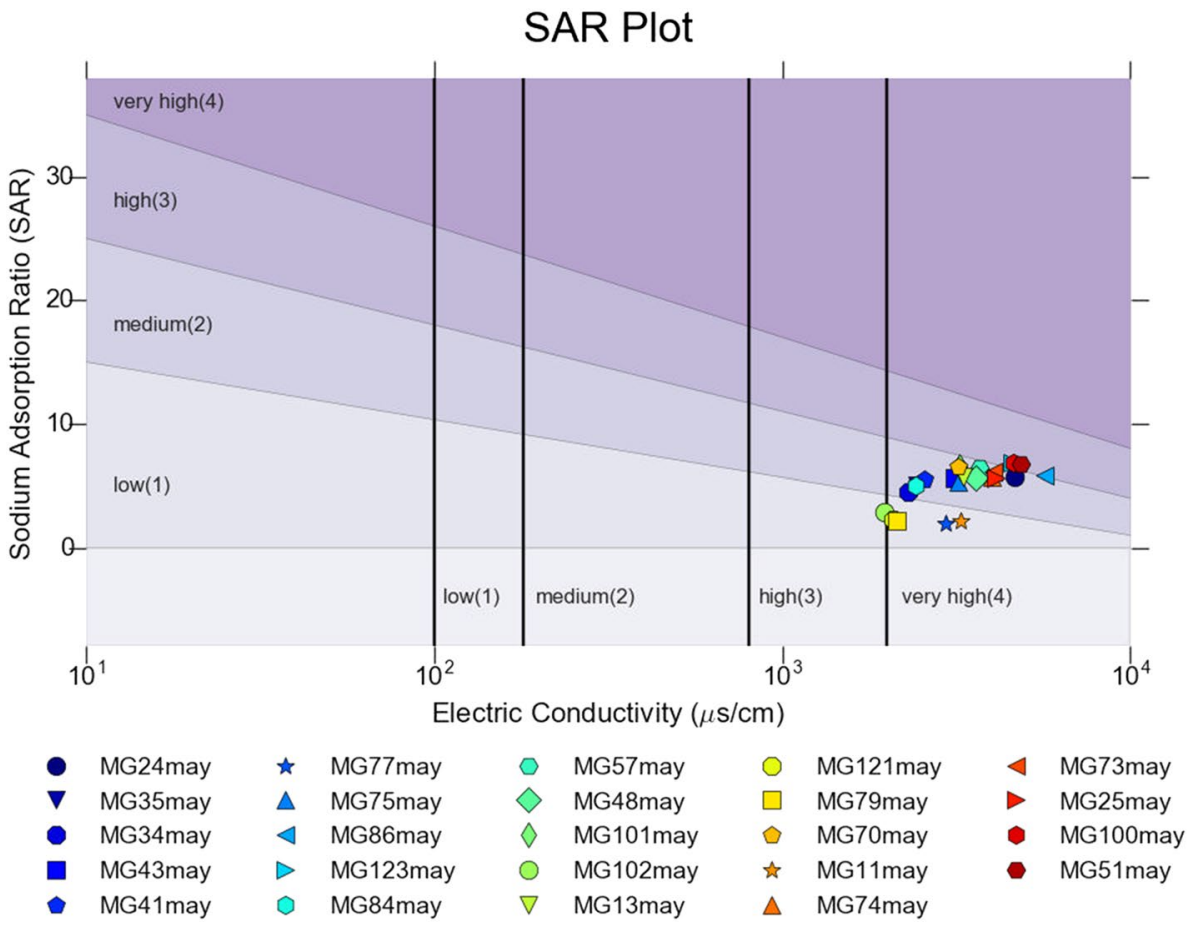

Fig. 17 SAR plot for the karstic aquifer (May 2016)

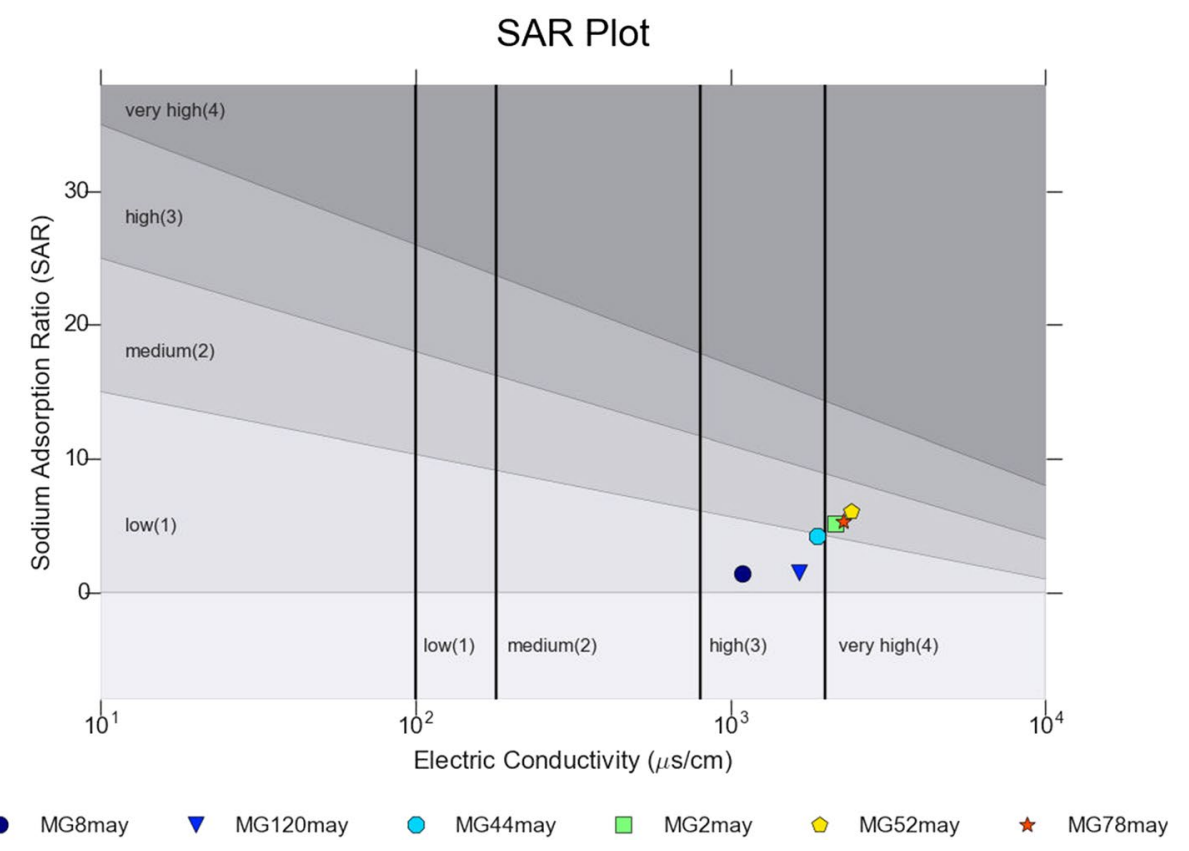

of karstic groundwater are also $\mathrm{Na}-\mathrm{Ca}-\mathrm{Cl}$, a fact that proves the hydraulic connection of the two aquifer units. Four samples are plotted between the intrusion and the mixing zone, while two of them are plotted between the mixing and fresh zone, a fact that highlights a better quality of groundwater in the karstic unit than the alluvial unit.

SAR diagrams of Figs. 16 and 17, present the evaluation of groundwater suitability for irrigation purposes, in the unconsolidated and karstic formation respectively.
The SAR diagram for the alluvial aquifer suggests a very high salinity and a low to high range of sodium hazard to plants, for most of the samples. The karstic aquifer samples are less hazardous for the crops as the level of salinity ranges between high to very high and the sodium absorption is low to medium. To evaluate groundwater nitrate contamination according to a European legislation, the tool "Parameter Normative Map" of AkvaGIS was used. 
Fig. 18 Nitrates classification according to the EU Nitrates Directive (Council Directive 91/676/EEC) limits (October 2016)

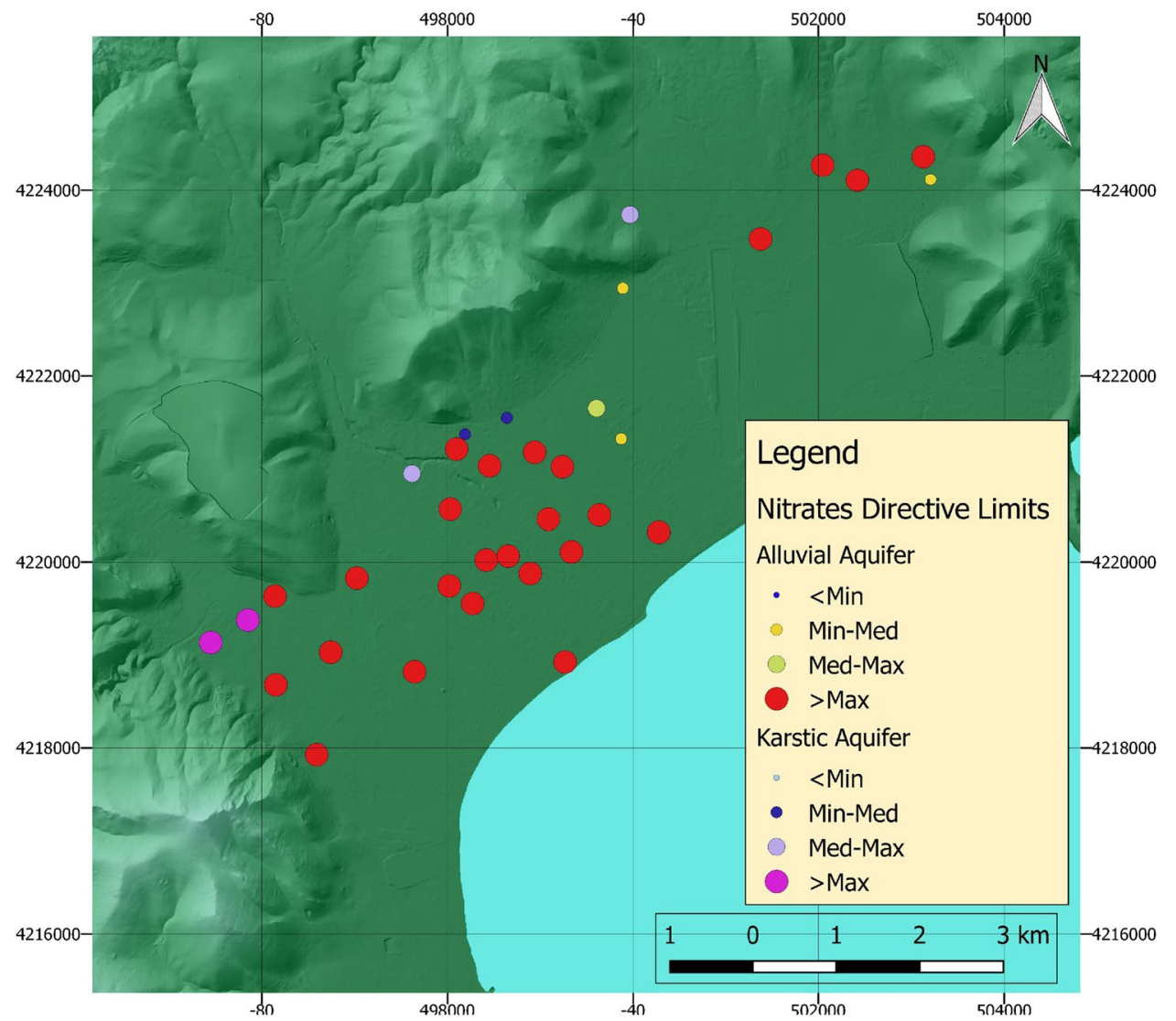

due to the different hydrodynamic conditions of the system, its great extend and the fact that the karstic formation in Marathon plain is covered at its bigger part from the shallow unconsolidated layer.

\section{Conclusions}

AkvaGIS is an integrated hydrogeological analysis tool composed by a geospatial database implemented in Spatialite and a set of tools for improving the management, visualization and interpretation of hydrogeological and hydrochemical data. AkvaGIS was developed to complement the functionalities of FREEWAT water resources modeling platform within the widely known open source GIS environment, QGIS. This ICT tool proved that it successfully achieved:

(i) to manage and query the hydrochemical measurements performed in groundwater wells, piezometers, springs, etc. stored in the database;

(ii) to apply one or several query criteria (e.g. time interval, groundwater measurement) and to combine them for advanced spatio-temporal queries on the hydrochemical data stored in the database;

(iii) to create thematic maps (e.g. ion distribution maps) of the selected points, time interval and parameters; 
(iv) to calculate some general statistics such as the minimum, maximum or average for each selected hydrochemical parameter,

(v) to create hydrochemical plots that can be used for the interpretation of the qualitative characteristics of investigated groundwater samples within the studied coastal aquifer system.

For the demonstration of the above, a coastal aquifer system in Marathon (Attica, Greece) was used as a reference site that presents typical hydro-environmental problems such as nitrate contamination and seawater intrusion, to present the capabilities of the software tool. Considering the results of the generated plots and the distribution maps, the main outcomes are.

- The coastal aquifer of the study area is contaminated by seawater intrusion, while the more affected areas in the upper unconfined aquifer layer are those in the vicinity to the coast as well as the central part of the study site, where the agricultural activities are rather extensive. Based on the generated SAR plots, the groundwater samples are characterized as unsuitable for irrigation purposes, due to their elevated sodium concentrations.

- The recorded nitrate concentrations are in many parts above the legal limits (Water Framework Directive and Nitrate Directive) for the majority of the samples in both formations.

- The generated piper plots indicate that the dominant groundwater type in the area is $\mathrm{Na}-\mathrm{Ca}-\mathrm{Cl}$ (for both formations) and the majority of the samples indicate ion exchange processes that take place as water-rock interactions during the phenomenon of seawater intrusion.

This research proves that AkvaGIS tool can provide a wide potential of applications for a thorough hydrogeological assessment such as: (i) management and visualization of hydrogeological and hydrochemical data, and (ii) hydrogeological and hydrochemical data integration within a GIS environment. Overall, AkvaGIS is a valuable tool for hydrochemical data management integrated in the FREEWAT plugin, a user-friendly platform for surface water and groundwater management. The user can store, update, and share campaign data in a free and open-source database to monitor and evaluate the progress of groundwater quality and quantity for different time periods, for several groundwater aquifer systems and for individual groundwater monitoring points.

Acknowledgements This paper is presented within the framework of the project FREEWAT, which has received funding from the European Union's Horizon 2020 research and innovation Programme under Grant
Agreement no. 642224. This paper content reflects only the authors' views and the European Union is not liable for any use that may be made of the information contained therein.

\section{References}

Alcaraz M (2016) GIS Platform for Management of Shallow Geothermal Resources. PhD Thesis. Polytechnic University of Catalunya, UPC (Spain)

Appelo C, Postma D (2005) Geochemistry, groundwater and pollution, 2nd edn. A.A Balkema Publishers, Great Britain

AQUAVeo (2017). GMS User Manual (v20.3)—Groundwater Modeling System, p 1404

Banta ER (2011) ModelMate-A graphical user interface for model analysis: U.S. Geological Survey Techniques and Methods 6-E4, p 31

Criollo R, Velasco V, Vázquez-Suné E, Serrano-Juan A, Alcaraz M, García-Gil A (2016) An integrated GIS-based tool for aquifer test analysis. Environ Earth Sci 75:391

Criollo R, Velasco V, Nardi A, de Vries LM, Riera C, Scheiber L, Juradod A, Brouyèree $S$, Pujadesf $E$, Rossetto R, Vázquez-Suñé E (2019) AkvaGIS: an open source tool for water quantity and quality management. Comput Geosci 127:123-132

Food and Agriculture Organization of the United Nations, International Telecommunication Union (2017) E-Agriculture in Action, Bangkok

Koumantakis I, Georgalas L, Morfopoulos Z (1993) Degradation of groundwater quality of the plain of Marathon. In: 2nd Hydrogeological Conference, Patras

Kundzewicz ZW, Hattermann FF (2008) Integrated River Basin management: harmonised modelling tools and decision-making process. the water framework directive: ecological and chemical status monitoring, pp. 181-194

Melissaris P, Stavropoulos X (1999) Hydrogeological assessment of the coastal plain of Marathon, Attica. In: Report submitted to the Ministry of Agriculture, Department of Land Reclamation, Athens

Miyata Y, Hata T (2013) ICT-Based remediation with knowledge information management for contaminated groundwater. Geotech Geol Eng 31:911-926

Pereira ÂG, Rinaudo JD, Jeffrey P, Blasques J, Quintana SC, Courtois N, Funtowicz S, Petit V (2003) ICT tools to support public participation in water resources governance \& planning: experiences from the design and testing of a multi-media platform. J Environ Assess Policy Manag 5(03):395-420

Perleros V (2001) Geological-Hydrogeological Assessment, In: Technical Report on Integrated Assessment for Planning and Development -including supporting research activities-for the construction of Schinias Olympic Rowing and Canoeing Centre. General Secretariat for Public Works, Athens

Poeter EP, Hill MC, Dan L, Tiedeman CR, Mehl S (2014) UCODE_2014, with new capabilities to define parameters unique to predictions, calculate weights using simulated values, estimate parameters with SVD, evaluate uncertainty with MCMC, and more. In: Integrated groundwater modeling center report number: GWMI 2014-02

Psychoyou M, Mimides T, Rizos S, Sgoubopoulou A (2007) Groundwater hydrochemistry at Balkan coastal plains-the case of Marathon of Attica, Greece. Desalination 213:230-237

Rizou S, Kenda K, Kofinas D, Mellios N, Pergar P, Ritsos PD, Vardakas J, Kalaboukas K, Laspidou C, Senožetnik M, Spyropoulou A (2018) Water4Cities: an ICT platform enabling holistic surface water and groundwater management for sustainable cities. Multidiscip Digit Publ Inst Proc 2(11):695 
Rossetto R, De Filippis G, Borsi I, Foglia L, Cannata M, Criollo R, Vázquez-Suñé E (2018) Integrating free and open source tools and distributed modelling codes in GIS environment for data-based groundwater management. Environ Model Softw 107:210-230

Sempere-Payá V, Todolí-Ferrandis D, Santonja-Climent S (2013) ICT as an enabler to smart water management. Smart sensors for realtime water quality monitoring. Springer, Berlin, Heidelberg, pp $239-258$

Siemos N (2010) Evaluation of water resources in Attica \& Islands of Argosaronic Gulf, Inst. of Geological and Mineral Exploration, Athens, $\mathrm{p} 148$

Sotiropoulos P, Tzanis A, Sideris G (2007) WatertoolTM: an automated system for hydrological investigations with application at the area of Kato Souli (NE Attica, Greece). Bulletin of the Geological Society of Greece, Vol. 37s

Tzanis A, Chailas S, Kranis C, Sotiropoulos P, Karmis P (2008) Geophysical investigation of hydrogeological conditions and salination processes at the Marathon-Kato Souli Basin (NE Attica, Greece). In: 8th international hydrogeological congress of Greece

Velasco V (2013) GIS-based Hydrogeological Platform for Sedimentary Media. PhD Thesis. Polytechnic University of Catalunya, UPC (Spain)
Velasco V, Tubau I, Vázquez-Suñé E, Gogu R, Gaitanaru D, Alcaraz M, Serrano-Juan A, Fernàndez-Garcia D, Garrido T, Fraile J, Sanchez-Vila X (2014) GIS-based hydrogeochemical analysis tools (QUIMET). Comput Geosci 70:164-180. https://doi. org/10.1016/j.cageo.2014.04.013

Waterloo Hydrogeologic (2017) User's Manual: Visual MODFLOW Flex 4.1. Integrated Conceptual \& Numerical Groundwater Modeling, p 615

Winston RB (2009) ModelMuse-A graphical user interface for MODFLOW-2005 and PHAST: U.S. Geological Survey Techniques and Methods 6-A29, p 52

Winston RB (2014) Modifications made to ModelMuse to add support for the Saturated-Unsaturated Transport model (SUTRA): U.S. geological survey techniques and methods, book 6, chap. A49, p 6. https://doi.org/10.3133/tm6a49

Publisher's Note Springer Nature remains neutral with regard to jurisdictional claims in published maps and institutional affiliations. 